\title{
A Pilot Study Comparing Two Physiotherapy TeChNiQues In Patients with Cystic Fibrosis
}

\begin{abstract}
The flutter is a simple hand held device designed to facilitate the mobilisation of excess bronchial secretions by means of oscillating positive pressure. Traditionally patients at the Johannesburg Hospital Cystic Fibrosis clinic used the active cycle of breathing technique as a means of facilitating secretion mobilisation and clearance. When the flutter became available in South Africa in 1999 many cystic fibrosis patients wanted to change to this technique. Minimal research has been conducted comparing these two techniques.
\end{abstract}

Milne SM, MSc Wits'; EALES CJ, PhD'

${ }^{1}$ Physiotherapist, Johannesburg Hospital. 2 School of Therapeutic Sciences, University of the Witwatersrand.

The aim of this pilot study was therefore to determine which technique is more effective in the mobilisation of secretions in cystic fibrosis patients.

The pilot study was conducted on seven cystic fibrosis patients (mean age 28 years, range 16-42 years) admitted to the Johannesburg Hospital for antibiotic therapy. The study lasted four days and consisted of two treatment days separated by a washout day on which no physiotherapy was performed. Patients randomised into Group A performed the flutter technique on day two and the active cycle of breathing technique on day four. Group B performed the active cycle of breathing technique on day two and the flutter on day four. The techniques were performed twice a day for 15 minutes. The measurements taken were daily 24-hour sputum samples and daily lung function tests. A questionnaire to determine patient preference to a technique concluded the study.

The results showed no statistical difference between the two techniques with regard to sputum weight or lung function $(p<0.05)$. The questionnaire indicated that on a whole, patients had no preference for a technique.

\section{KEY WORDS: CYSTIC FIBROSIS, PHYSIOTHERAPY, FLUTTER, ACTIVE CYCLE OF BREATHING TECHNIQUE.}

\section{INTRODUCTION}

Physiotherapy has become an integral part of cystic fibrosis management. It aims to improve ventilation and mucociliary clearance through the removal of tenacious and obstructing secretions. The removal of these secretions is thought to relieve atelectasis and prevent or slow the proteolytic destruction of airways by removing the substances likely to promote infection (Williams 1994).

The flutter and active cycle of breathing technique are only two of numerous independent physiotherapy techniques used in cystic fibrosis. The flutter was developed in Switzerland in the late 1980's (Butler 1998) and is one of the newer independent airway clearance techniques. It was not readily available in South Africa until the late 1990's when a local company started to manufacture flutter devices at an affordable price. The flutter is a hand held, pipe shaped device. Within it is housed a loosely supported steel ball, covered by a perforated cap. The patient exhales actively into the pipe, generating positive expiratory pressures of $10-25$ $\mathrm{cm} \mathrm{H}_{2} \mathrm{O}$. During exhalation the ball flutters in the pipe, generating oscillations to about $15 \mathrm{~Hz}$, which are transmitted through the airways (Hardy 1994). The flutter thus combines the techniques of positive expiratory pressure (PEP) with high frequency oscillations. The oscillating PEP prevents airway collapse and mucus clearance is enhanced by the vibrations and intermittent airflow accelerations produced by the movement of the ball (Prasad 1998; Pryor 1999).

Pryor et al (1991) renamed the forced expiratory technique (FET) the active cycle of breathing technique. This was done by including thoracic expansion and breathing control with FET. The active cycle of breathing technique is the most commonly used airway clearance techniques in both New Zealand (Butler 1998) and the United Kingdom (Prasad 1998). The first component of the active cycle is FET. In 1979 FET was defined by Pryor and Webber as one or two forced expirations or huffs from mid- lung volume to low-lung volume (this being the range through which more peripheral secretions are mobilised), followed by diaphragmatic breathing or breathing control. As secretions reach the upper airways one or two huffs, at high-lung volumes, are used to clear them (Partridge 1989). The second component of the active cycle of breathing is thoracic expansion. Thoracic expansions are deep breaths with the emphasis on maximum inspiration, an inspiratory pause and passive, relaxed expiration. Increased lung volume during thoracic expansion allows air to get behind distal secretions, via collateral ventilatory channels, and thus assist in their mobilisation (Prasad 2000). The third compo-

\section{CORRESPONDENCE TO:}

SM Milne

Johannesburg Hospital

Physiotherapy Department

Tel: (011) 488-4210

Fax: (011) 488-4341

E-mail: kezley@worldonline.co.za 
nent of the active cycle of breathing is breathing control. This is gentle breathing using the patients' preferred respiratory rate. It is used between the more active components of the cycle. It is used between thoracic expansions as a period of relaxation and between huffing to avoid airflow obstruction (Prasad 1993).

There are only a few studies that directly compare these two techniques. The results are conflicting. Pryor et al (1994) recommended that the flutter should not be used in combination with the active cycle of breathing technique. Pike et al (1999) found that the two techniques were equally effective.

The physiotherapist working in the paediatric cystic fibrosis clinic at the Johannesburg Hospital noticed that the active cycle of breathing technique often became boring and tedious for these young patients. This affected their already poor adherence with physiotherapy. It was further noted that patients seemed to enjoy and were more willing to use the flutter device. The feeling of the therapist, parents and patients was that the flutter was more effective than the active cycle of breathing technique but as mentioned the available literature was conflicting. The aim of this pilot study was to determine which technique, the flutter or the active cycle of breathing technique was more effective in the removal of secretions in patients suffering from cystic fibrosis.

\section{METHOD}

\section{Patients}

Seven cystic fibrosis patients, four male and three female, with a mean age of 28 years (range 16-42 years) participated in this study.

\section{The follow ing were the inclusion criteria:}

- Patients with cystic fibrosis diagnosed by either sweat test (sweat sodium concentration $>70 \mathrm{mmol} / \mathrm{l}$ ) or genetic testing.

- Patients admitted for a course of intravenous antibiotics.

- Patients who were old enough to perform lung function tests effectively.

- Patients who were able to perform the two physiotherapy techniques.
Exclusion criteria:

- Patients with frank haemoptysis or a pneumothorax.

- Patients admitted for terminal care.

Written informed consent was obtained.

\section{Study Design}

Participants were randomised into two groups, either group A or B. Group A would do the flutter on the first treatment day and the active cycle of breathing technique on the second treatment day. Group B would do the active cycle of breathing technique on the first treatment day, followed by the flutter on the second treatment day. There was a washout day, in which no physiotherapy was done, prior to the first treatment day and in between the first and second treatment days.

\section{Measurements}

Daily lung function tests were done in the Johannesburg Hospital Lung Function Laboratory. Simple spirometry tests were done using a Jaeger Master Scope spirometer. The measurements taken were forced expiratory volume in one second $\left(\mathrm{FEV}_{1}\right)$, forced vital capacity (FVC), the ratio of $\mathrm{FEV}_{1} / \mathrm{FVC}$, peak expiratory flow rate (PEF), forced expiratory flow at 25-75\% (FEF 25-75), forced vital capacity during inspiration (FVC IN) and forced inspiratory flow rate at $50 \%$ (FIF50).

A 24-hour sputum sample was collected on each day of the study. Sputum was expectorated into a preweighed sputum container. Net sputum weights were calculated using a Shimadzu LIBROR AEU 210 scale. Wet sputum samples were collected, as the equipment needed to obtain dry sputum pellets was not available to the researcher for this pilot study.

A simple questionnaire, compiled by the researcher, was completed by the participants at the end of the study. The main purpose of the questionnaire was to determine which technique participants preferred and if they were going to change the physiotherapy technique they routinely used to one in the study.

\section{Physiotherapy Techniques}

All physiotherapy sessions were pre- ceded by the patients' usual nebulisation therapy. The researcher supervised the physiotherapy sessions. Both techniques were done for 15 minutes twice a day.

\section{- The Flutter Technique}

In a sitting position participants placed the flutter device into their mouth, creating a tight seal with their lips. The participant exhaled 10-15 times through the flutter. This was followed by the forced expiratory technique. The forced expiratory technique for this study was defined as follows, three forced expirations (huffs) at mid to low lung volumes, followed by three normal breaths at the patients preferred rate and tidal volume (controlled breathing), followed by three huffs at high lung volumes. The participant was encouraged to cough and expectorate if necessary. The cycle started again with 10-15 breaths through the flutter, followed by the forced expiratory technique, coughing and expectoration. This cycle was repeated for 15 minutes.

\section{- The Active Cycle Of Breathing Technique (ACBT)}

This technique was also done in a sitting position. The ACBT for this study consisted of thoracic expansions, controlled breathing and the forced expiratory technique and coughing. The thoracic expansions were repeated three to four times. The patient then took three to four breaths at their own rate and tidal volume (controlled breathing). This was followed by another set of three to four thoracic expansions and another set of controlled breathing. Forced expiratory technique, as described above, was then performed and the patient was encouraged to cough and expectorate. This cycle was repeated for 15 minutes.

\section{STATISTICAL ANALYSIS}

Due to the study design and sample size the Wilcoxon's matched pairs signed ranks test was used to analyse the data. The software used was STATISTIX for windows V2:0. A p-value of less than 0.05 was considered statistically significant. 


\section{RESULTS}

Data from seven participants were collected over a ten month period.

\section{Sputum Weight}

In table 1 the summary statistics of 24-hour sputum weights are presented.

In table 2 the 24-hour sputum weights, of the seven participants, post active cycle of breathing technique, flutter and washout are presented.
To compare the treatment and washout days the Wilcoxon's matched pairs signed ranks test was used to determine the p-value. The 24-hour sputum weight values, reflected in table 2 , were used in these calculations. In table 3 these p-values are presented.

None of these results were of statistical significance as none of the p-values calculated were less than 0.05 .

Table 1: Summary statistics of 24-hour sputum weights of the seven participants.

\begin{tabular}{|l|c|c|c|c|c|}
\hline Parameter & Minimum & Median & Maximum & Mean & $\begin{array}{c}\text { Standard } \\
\text { deviation }\end{array}$ \\
\hline $\begin{array}{l}\text { 24-hour sputum weight } \\
\text { post acbt (grams) }\end{array}$ & 1.42 & 18.47 & 46.65 & 22.72 & 16.07 \\
\hline $\begin{array}{l}\text { 24-hour sputum weight } \\
\text { post flutter (grams) }\end{array}$ & 8.34 & 18.81 & 44.66 & 24.28 & 13.76 \\
\hline $\begin{array}{l}\text { 24-hour sputum weight } \\
\text { post washout (grams) }\end{array}$ & 0.0 & 14.05 & 54.02 & 18.34 & 17.18 \\
\hline
\end{tabular}

Table 2: 24-hour sputum weights post active cyde of breathing technique, flutter and washout.

\begin{tabular}{|c|c|c|c|}
\hline Participant & $\begin{array}{c}\text { 24-Hour } \\
\text { Sputum Weight } \\
\text { Post Flutter } \\
\text { (Grams) }\end{array}$ & $\begin{array}{c}\text { 24-Hour Sputum } \\
\text { Weight Post Active } \\
\text { Cycle of Breathing } \\
\text { Technique (Grams) }\end{array}$ & $\begin{array}{c}\text { 24-Hour Sputum } \\
\text { Weight Post } \\
\text { Washout } \\
\text { (Grams) }\end{array}$ \\
\hline 1. & 8.34 & 1.42 & 0 \\
\hline 2. & 14.25 & 7.59 & 8.87 \\
\hline 3. & 23.8 & 29.23 & 13.45 \\
\hline 4. & 18.81 & 18.47 & 14.05 \\
\hline 5. & 18.42 & 18.32 & 22.84 \\
\hline 6. & 41.65 & 46.65 & 15.17 \\
\hline 7. & 44.66 & 37.36 & 54.02 \\
\hline
\end{tabular}

Table 4: Mean values of lung function tests at baseline, post active cycle of breathing technique, post flutter and post washout.

\begin{tabular}{|c|c|c|c|c|}
\hline Parameter & At Baseline & Post ACBT & Post Flutter & Post Washout \\
\hline FEV $_{1}(\mathrm{~L})$ & 1.23 & 1.34 & 1.38 & 1.36 \\
\hline FVC(L) & 2.85 & 2.98 & 2.98 & 3.02 \\
\hline RATIO (\%) & 45.62 & 47.55 & 49.09 & 47.43 \\
\hline PEF(L/ S) & 4.44 & 4.7 & 4.88 & 4.80 \\
\hline FEF 25 (L/ S) & 1.17 & 1.56 & 1.77 & 1.52 \\
\hline FEF 50 (L/ S) & 0.47 & 0.61 & 0.81 & 0.65 \\
\hline FEF 75 (L/ S) & 0.17 & 0.19 & 0.3 & 0.24 \\
\hline
\end{tabular}

$\mathrm{ACBT}=$ Active cycle of breathing technique

\section{Pulmonary Lung Function Tests}

Mean values were calculated for $\mathrm{FEV}_{1}(\mathrm{l}), \mathrm{FVC}(1)$, Ratio $\mathrm{FEV}_{1} / \mathrm{FVC}(\%)$, PEF(1/s), FEF $25(1 / \mathrm{s})$, FEF 50(1/s) and FEF $75(1 / s)$ at baseline, post washout, post active cycle of breathing technique and post flutter. These values are reflected in table 4.

In order to draw comparisons between the active cycle of breathing technique and the flutter, a mean value for the change from baseline or washout, depending on randomisation, was calculated for each technique. To determine which technique was associated with the greatest improvement these values for the change from baseline or washout were further evaluated using the Wilcoxon's matched pairs signed rank test and a p-value was calculated. These results are presented in table 5.

None of these results are statistically significant as none of the p-values are less than 0.05 .

Table 3: Comparison of 24-hour sputum weights of the seven participants.

\begin{tabular}{|l|c|}
\hline \multicolumn{1}{|c|}{ Parameter } & P-Value \\
\hline ACBT versus Flutter & 0.27 \\
\hline ACBT versus W a shout & 0.34 \\
\hline Flutter versus W ashout & 0.11 \\
\hline
\end{tabular}

$\mathrm{ACBT}=\mathrm{A}$ ctive cycle of breathing technique.

Table 5: Comparison of the changes from baseline/ washout for the active cycle of breathing technique and the flutter.

\begin{tabular}{|l|c|}
\hline Parameter & P-Value \\
\hline FEV $_{1}(\mathrm{l})$ & 0.50 \\
\hline FVC (I) & 0.40 \\
\hline Ratio(\%) & 0.93 \\
\hline PEF(I/ s) & 0.67 \\
\hline FEF 25(l/ s) & 0.83 \\
\hline FEF 50(I/ s) & 0.67 \\
\hline FEF 75(I/ s) & 0.93 \\
\hline
\end{tabular}


Table 6: Physiotherapy techniques used pre and post study.

\begin{tabular}{|l|l|l|}
\hline Participant & \multicolumn{1}{|c|}{$\begin{array}{c}\text { Technique Being Used Prior } \\
\text { To Study }\end{array}$} & \multicolumn{1}{|c|}{$\begin{array}{c}\text { Technique To Use } \\
\text { Post Study }\end{array}$} \\
\hline 1. & Breathing exercises. & Flutter. \\
\hline 2. & ACBT + percussion. & ACBT + flutter. \\
\hline 3. & Conventional chest physiotherapy. & ACBT. \\
\hline 4. & Flutter. & Flutter. \\
\hline 5. & Breathing exercises. & ACBT. \\
\hline 6. & N o physiotherapy. & ACBT + flutter. \\
\hline 7. & Flutter + breathing exercises. & ACBT. \\
\hline
\end{tabular}

$\mathrm{ACBT}=$ A ctive cycle of breathing technique.

\section{Questionnaire Responses}

Two participants (29\%) preferred using the flutter. Three participants $(43 \%)$ preferred the active cycle of breathing technique, whilst two participants (29\%) liked the techniques equally. The reasons the participants gave for preferring the flutter was that it was more effective and time passed quicker. The active cycle of breathing technique was preferred because it was relaxing, less tiring, easier to do, more effective and could be done anywhere because you do not need a device. No major side effects were experienced with either technique. Table 6 summarises the physiotherapy techniques being used prior to the study and the techniques to which the participant was going to change after the study.

\section{DISCUSSION}

The aim of this pilot study was to determine which technique, the active cycle of breathing technique or the flutter was the most effective in the treatment of patients with cystic fibrosis. The results indicated that there was no significant difference between the two airways clearance techniques, whether using 24-hour sputum weights or lung function parameters as outcome measures.

One of the major limitations of this study is the small sample size of seven participants. This, despite the fact that the Johannesburg Hospital is one of the main cystic fibrosis centres in Gauteng. Even with a recruitment period of one year the number of participants remained small. There was a lack of paediatric patients due to the policy of paediatric clinics to administer home intra-venous antibiotics. This was a short-term study involving two, one-day treatment periods. It is possible that the positive changes attributed to the physiotherapy techniques under study are so small that they are not detectable in a single treatment day and only reach clinical significance over a longer time. The researcher was not blinded.

Other studies have also found that there is no one superior airways clearance technique in the removal of secretions in patients with cystic fibrosis. These findings should encourage clinical physiotherapists not to become obsessed with finding the "best" technique. They should avoid blanket prescription of airway clearance techniques and view the patient as an individual. With a thorough knowledge of the available techniques, the physiotherapist should assess each patient's clinical, social and economic circumstances and then formulate an effective and flexible management plan. It must be remembered that there is a very poor adherence with physiotherapy airway clearance techniques in cystic fibrosis. If a patient likes and feels confident with a technique they are more likely to remain compliant.

Future studies need to make use of extended treatment periods. Multicentred studies may result in a larger sample size. Pre and post treatment lung functions would determine the exact response to the physiotherapy technique.

Physiotherapists routinely advocate airway clearance techniques in cystic fibrosis on intuitive reasoning rather than scientific evidence. Universal acceptance of these airway clearance techniques currently makes it ethically difficult to attempt a controlled trial of treat- ment versus no treatment. With current emphasis on evidence-based medicine, such a study would be of immeasurable value. However, future studies could attempt to identify whether certain treatments have a therapeutic advantage in certain situations, therefore providing clearer guidelines of treatment choice.

\section{ACKNOWLEDGEMENTS}

The author wishes to thank Professor C J Eales for her support and encouragement.

Dr. Becker for his advice on the statistical analysis.

Mr Van Der Westhuizen for performing the lung function tests and to the participants from whom I learned so much and thoroughly enjoyed the time we spent together.

\section{REFERENCES}

Butler SG 1998 Current airway clearance techniques. New Zealand Medical Journal 111: $183-186$

Hardy KA 1994 A review of airway clearance: New techniques, indications and recommendations. Respiratory Care 39(5): 440-452

Partridge C, Pryor J, Webber B 1989 Characteristics of the forced expiration technique. Physiotherapy 75(3): 193-194

Pike SE, Machin AC, Dix KJ, Pryor JA, Hodson ME 1999 Comparison of flutter VRP1 and forced expirations with the active cycle of breathing technique in patients with cystic fibrosis. The Netherlands Journal of Medicine 54: S55-S56

Prasad SA 1993 Current concepts in physiotherapy. Journal of the Royal Society of Medicine 86(suppl 20): 23-29

Prasad SA, Main E 1998 Finding evidence to support airway clearance techniques in cystic fibrosis. Disability and Rehabilitation 20: $235-246$

Prasad SA, Tannenbaum E, Mikelsons C 2000 Physiotherapy in cystic fibrosis. Journal of the Royal Society of Medicine 93(suppl 38): 27-36

Pryor JA 1999 Physiotherapy for airway clearance in adults. European Respiratory Journal 14: 1418-1424

Pryor JA 1991 The forced expiratory technique. In: Respiratory Care. Pryor JA(editor) Churchill Livingstone, London: 79-100

Williams MT 1994 Chest physiotherapy and cystic fibrosis. Why is the most effective form of treatment still unclear? Chest 106: $1872-1882$ 